\title{
Mastocytosis: One Word for Different Diseases
}

\author{
Marianna Criscuolo (D) - Luana Fianchi · Alessio M. E. Maraglino • \\ Livio Pagano
}

Received: September 11, 2018 / Published online: October 29, 2018

(c) The Author(s) 2018

\begin{abstract}
Mastocytosis is a neoplastic disease originating from tissue infiltration by transformed mast cells. The diagnosis requires a high grade of suspicion due to the large variety of presenting symptoms. The World Health Organization classification recognizes localized (cutaneous) and systemic forms of the disease, with these forms showing different degrees of aggressiveness. Mastocytosis is often a multiorgan disease, and its correct management requires a multidisciplinary team of experienced consultants to provide overall patient care. Bone marrow evaluation by molecular analyses, skeleton $\mathrm{X}$-ray and abdominal scan together with allergologic and dermatologic evaluation constitute the essential diagnostic work-up for adult patients with mastocytosis. As clinical
\end{abstract}

Enhanced Digital Features To view enhanced digital features for this article go to https://doi.org/10.6084/ m9.figshare.7195607.

M. Criscuolo $(\bowtie) \cdot$ L. Fianchi

Dipartimento di Scienze Radiologiche

Radioterapiche ed Ematologiche, Fondazione

Policlinico Universitario A. Gemelli IRCCS, Rome, Italy

e-mail: marianna.criscuolo@policlinicogemelli.it

A. M. E. Maraglino · L. Pagano

Dipartimento di Scienze Radiologiche

Radioterapiche ed Ematologiche, Fondazione

Policlinico A. Gemelli IRCCS-Università Cattolica

del Sacro Cuore, Rome, Italy situations vary, treatment options range from the use of drugs to treat the symptoms, such as anti-H1 receptors and steroids, to UV irradiation, which is overwhelmingly used in patients with cutaneous mastocytosis (CM) or indolent systemic mastocytosis, to cytoreductive treatment to control life-threatening symptoms or organ damage in the more aggressive forms of the disease. Prognosis also widely differs among patients diagnosed with mastocytosis, with the spectrum ranging from an almost normal life expectancy for those with $\mathrm{CM}$ and to less than 1-year median overall survival for those with mast cell leukemia.

Keywords: Anaphylaxis; Cladribine; Invasive procedures; Mastocytosis; Pregnancy; Systemic mastocytosis

\section{INTRODUCTION}

The term mastocytosis refers to a wide range of neoplastic diseases originating from the infiltration of tissue by transformed mast cells. The signs, symptoms and clinical presentations, which are highly variable, depend on the distinct functions of the mast cells that are involved in the acute phase of inflammation and mediate allergic response.

Mast cells are normally present in the skin, gastro-intestinal (GI) tract and bone marrow, 
where their contact with endogenous or exogenous antigens leads to the release of several mediators acting on endothelial, smooth muscle and nervous cells and subsequent recruitment of other inflammation cells. Abnormal activity of mast cells causes hypersensitivity diseases, such as augmented allergic reactions, asthma and urticaria, but also plays a role in autoimmune diseases and chronic skin inflammation. When a neoplastic transformation occurs, mast cells accumulate prevalently in the skin and bone marrow and are responsible for the allergic symptoms that are in most cases the main complaints of patients.

The incidence of mastocytosis is not known due to rarity of disease and protean clinical manifestations, but it has been reported in a Danish study to be 0.89 per $100,000 /$ year [1].

The diagnosis of mastocytosis requires a high grade of suspicion because the presenting symptoms may vary from the most reported symptoms, such as facial flushing and dizziness, skin reddish lesions and pruritus, respiratory discomfort with breath difficulties, to constitutional (sweating, fatigue, palpitation), GI (nausea, vomiting, abdominal pain, diarrhea), musculoskeletal and neurological symptoms (myalgia, bone pain and fractures, headache, depression and panic attack) and to hypotension, syncope and life-threatening anaphylactic shock. Attacks of mast cell degranulation are often unpredictable and can be triggered by physical factors, such as heat/cold variation and physical exertion, the consumption of certain food and/or alcohol, the use of drugs, such as nonsteroidal anti-inflammatory drugs, emotional stress and hymenoptera venoms.

The aim of this paper was to review the World Health Organization (WHO) classification, clinical characteristics and management of adult mastocytosis. This review is based on previously conducted studies and does not contain any studies with human participants or animals performed by any of the authors.

\section{WHO CLASSIFICATION}

In the most recent WHO classification of mastocytosis, the disorder was included in the group of myeloproliferative neoplasms [2] (Table 1). However, several nosological entities are recognized, and expert panels frequently revise the classification [3].

Cutaneous mastocytosis (CM) is defined as an isolated skin infiltration without signs of bone marrow involvement that typically presents with small, round, reddish or brown lesions. CM most frequently presents as maculopapular CM (also known as urticaria pigmentosa), with two variants, namely, monomorphic and polymorphic infiltrates. More rare presentations are diffuse CM and cutaneous mastocytoma [3]. The flare-up of lesions but not of normal skin after moderate rubbing, referred to as Darier's sign, is evocative of disease and is a reliable physical finding. Minor criteria of $\mathrm{CM}$ are an increased number of mast cells and the identification of mutations causing constitutive activation of the oncogenic tyrosine kinase KIT in abnormal tissue, even if the number of mast cells in healthy skin varies according to cutis layers and parts of the body [4]. CM is typically found in children and tends to disappear during adolescence; isolated CM is only rarely found in adults, and when found it is often associated to bone marrow involvement.

Systemic mastocytosis (SM) is characterized by the presence of multifocal dense infiltrates, each composed of at least 15 mast cells, identified in the bone marrow and/or other extracutaneous organs (Table 2). Minor essential criteria are an atypical or immature morphology, presence of mutations causing constitutive activation of KIT based on molecular analysis, abnormal CD2 and/or CD25 expression based on flow cytometry analysis and constant serum tryptase level at $>20 \mathrm{ng} / \mathrm{ml}$. A diagnosis of SM can be made if the major criterion and one of more of the minor criteria are met. According to markers of high burden disease (B findings: > $30 \%$ infiltration in the bone marrow, a serum tryptase level of $>200 \mathrm{ng} / \mathrm{ml}$, signs of dysplasia or proliferation not diagnostic of another hematological malignancy [HM], abnormal size of the liver, spleen or lymph nodes without impaired function) or of end organ damage (C findings: cytopenia due to massive bone marrow infiltration, impaired liver function with ascites and/or portal hypertension, 
Table 1 World Health Organization of mastocytosis

\begin{tabular}{|c|c|c|c|}
\hline $\begin{array}{l}\text { WHO } \\
\text { categories }\end{array}$ & Subtypes & Diagnostic criteria & Characteristics \\
\hline \multirow{3}{*}{$\begin{array}{l}\text { Cutaneous } \\
\text { mastocytosis }\end{array}$} & Urticaria pigmentosa & \multirow[t]{3}{*}{ Immunohistochemistry } & Reddish papular lesions \\
\hline & Diffuse cutaneous mastocytosis & & $\begin{array}{l}\text { Reddish diffuse thickening } \\
\text { of skin }\end{array}$ \\
\hline & Solitary mastocytoma of skin & & $\begin{array}{l}\text { Brownish-yellow, } \\
\text { minimally elevated } \\
\text { plaque }\end{array}$ \\
\hline \multirow{5}{*}{$\begin{array}{l}\text { Systemic } \\
\text { mastocytosis }\end{array}$} & Indolent SM & \multirow{5}{*}{$\begin{array}{l}\text { Diagnostic criteria of } \\
\text { SM }\end{array}$} & No C findings ${ }^{a}$ \\
\hline & & & $\begin{array}{l}\text { At least } 2 \mathrm{~B} \text { findings }{ }^{\mathrm{a}} \text { and } \\
\text { no } \mathrm{C} \text { findings }\end{array}$ \\
\hline & & & Isolated BM mastocytosis \\
\hline & Aggressive SM & & At least one $\mathrm{C}$ findings \\
\hline & $\begin{array}{l}\text { SM associated to associated clonal hematological } \\
\text { non mast cell lineage disease }\end{array}$ & & $\begin{array}{l}\text { WHO criteria for a clonal } \\
\text { hematological neoplasm }\end{array}$ \\
\hline \multirow{3}{*}{$\begin{array}{l}\text { Mast cell } \\
\text { leukemia }\end{array}$} & & \multirow{3}{*}{$\begin{array}{l}\text { Diagnostic criteria of } \\
\text { SM }\end{array}$} & $\mathrm{BM}$ smear $>20 \% \mathrm{MC}$ \\
\hline & & & $\begin{array}{l}\text { BM biopsy diffuse } \\
\text { infiltration of immature } \\
\text { MC }\end{array}$ \\
\hline & & & $\mathrm{PB}$ smear $>10 \% \mathrm{MC}$ \\
\hline \multirow[t]{2}{*}{ Mast cell sarcoma } & & \multirow[t]{2}{*}{ No criteria for SM } & Isolated $\mathrm{MC}$ tumor \\
\hline & & & Destructive growth pattern \\
\hline \multirow{2}{*}{$\begin{array}{r}\text { Extracutaneous } \\
\text { mastocytoma }\end{array}$} & & \multirow[t]{2}{*}{ No criteria for SM } & Isolated $\mathrm{MC}$ tumor \\
\hline & & & $\begin{array}{l}\text { Non-destructive growth } \\
\text { pattern }\end{array}$ \\
\hline
\end{tabular}

$B M$ Bone marrow, $M C$ mast cells, $P B$ peripheral blood, $S M$ systemic mastocytosis, $W H O$ World Health Organization

${ }^{a}$ See text and Table 2 for description of $\mathrm{B}$ and $\mathrm{C}$ findings

hypersplenism, osteolytic bone lesions and/or pathological fractures, malabsorption and weight loss), SM is further classified as indolent SM (ISM; no B or C findings), smoldering SM (SSM, at least two B findings but no C findings) and aggressive SM (ASM, at least one $\mathrm{C}$ finding).

Two other categories of SM are SM associated to a clonal hematological non-mast cell lineage disease (SM-AHNMD) in which WHO diagnostic criteria for another $\mathrm{HM}$ are satisfied, and mast cell leukemia (MCL), in which $>20 \%$ and
$>10 \%$ mast cells are recorded in bone marrow aspirate and peripheral blood smears, respectively.

In patients with symptoms of hypersensitivity and an abnormal MC population expressing CD2 and/or CD25 and/or mutations causing constitutive activation of KIT and $<15$ mast cells in small aggregates, the correct diagnosis is monoclonal mast cell activation syndrome. 
Table 2 World Health Organization diagnostic criteria for systemic mastocytosis

\begin{tabular}{|c|c|c|}
\hline $\begin{array}{l}\text { Diagnostic } \\
\text { criteria }\end{array}$ & Organs & Characteristics \\
\hline \multirow[t]{2}{*}{ Major criteria } & $\mathrm{BM}$ & Multifocal, dense infiltrate of $>15$ aggregated MC \\
\hline & Others (except skin) & \\
\hline \multirow[t]{5}{*}{ Minor criteria } & BM & Immature and/or atypical $\mathrm{MC}>25 \%$ in aggregates \\
\hline & Others (except skin) & Spindle-shaped and/or atypical MC $>25 \%$ in aggregates \\
\hline & BM, PB, others (except skin) & Activating mutation at codon 816 \\
\hline & & Surface expression of CD2 and/or CD25 together with MC markers \\
\hline & Serum & Total tryptase persistently $>20 \mathrm{ng} / \mathrm{ml}$ \\
\hline \multirow[t]{4}{*}{ B findings } & BM & Infiltration $>30 \% \mathrm{MC}$ \\
\hline & & Dysplasia or myeloproliferation insufficient for diagnosis of AHNMD \\
\hline & & Almost normal blood count \\
\hline & Liver, spleen, nodes & Enlargement without impaired function \\
\hline \multirow[t]{9}{*}{ C findings } & BM & Cytopenia without other hematological neoplasm \\
\hline & Liver & Impaired function \\
\hline & & Aascites \\
\hline & & Portal hypertension \\
\hline & Bones & Osteolysis \\
\hline & & Pathological fractures \\
\hline & Spleen & Enlargement and hypersplenism \\
\hline & GI & Malabsorption \\
\hline & & Weight loss \\
\hline
\end{tabular}

AHNMD Associated clonal hematological non-mast cell lineage disease, GI gastro-intestinal

\section{CLINICAL PRESENTATION}

\section{Cutaneous Lesions}

The most frequent presentation of adult mastocytosis is the appearance of small reddish or brown maculopapular lesions, starting from the lower trunk and thigh and generally spreading to all of the body surface except the face. Differently from childhood onset, where lesions are typically polymorphic, are not associated with organ infiltration and disappear after puberty in most cases, adult mastocytosis is almost always associated with bone marrow involvement. On the other hand, cutaneous involvement may lack in advanced SM [3].

Patients presenting with evocative lesions should undergo skin biopsy to confirm neoplastic mast cell infiltration: this condition is referred to as mastocytosis in the skin (MIS) before involvement of other organs can be excluded by bone marrow evaluation with flow cytometry and molecular and immunohistochemistry analyses.

\section{Anaphylaxis}

Anaphylaxis is a potentially life-threatening hypersensitivity reaction involving at least two 
of the following: cutaneous, cardiovascular and respiratory systems and GI tract. Although the prevalence of allergy in patients with mastocytosis is comparable to that in the general population $[5,6]$, the former show an increased prevalence of anaphylaxis; moreover, anaphylaxis can be the presenting symptom, especially in patients without MIS. Anaphylaxis can be triggered by a Hymenoptera sting, food, drugs, anxiety, hot or cold exposure, rapid change of room temperature and/or exercise $[7,8]$. In a recent study in which 3374 patients complaining of an allergic disease were referred to outpatient clinic, tests for serum tryptase showed levels of $>15 \mathrm{ng} / \mathrm{ml}$ in $3 \%$ (96) of patients. Among these 96 patients, 30 showed persistently elevated serum tryptase levels of $>20 \mathrm{ng} /$ $\mathrm{ml}$, with 15 showing mast cell infiltration diagnostic for mastocytosis (12 cases of SM and 3 cases of $\mathrm{CM}$ ). Moreover, the elevated level of tryptase in these patients was statistically significantly higher than that found in other hypersensitivity conditions [9].

In recent years, an association has been found between anaphylaxis, tryptase levels and mastocytosis. Bonadonna et al. recently evaluated 379 patients with a systemic reaction due to Hymenoptera venom and showed that 44 of these patients $(11.6 \%)$ had a serum tryptase level that was persistently above the normal value $(11.4 \mathrm{ng} / \mathrm{ml})$ [10]. Taking into consideration that mastocytosis is a risk factor for anaphylaxis after Hymenoptera stings [10], they also performed bone marrow evaluation in 34 of 43 adult patients; according to cut-off value used, clonal mast cell disease was diagnosed in $50 \%$ and $88 \%$ of the evaluated patients with serum tryptase levels of $>20 \mathrm{ng} / \mathrm{ml}$ and $>11.4 \mathrm{ng} / \mathrm{ml}$ respectively [11].

In adult patients, neither the extent of cutaneous involvement or allele burden of the KIT D816 V mutation correlates with risk of anaphylaxis $[8,12]$, while levels of serum tryptase seem to be higher among patients with anaphylaxis [7].

Although performing a bone marrow biopsy may be resisted by these patients, there are sufficient evidence to validate the need for a complete diagnostic work-up in selected patients with anaphylaxis and a persistently high serum tryptase, especially when specific immunoglobulin (Ig) E and allergy tests are negative. In the case of a diagnosis of SM it is important to start immunotherapy and to try to prevent situations and behavior that trigger attacks, as well as to schedule a timely follow-up considering the risk of disease progression.

Serum tryptase levels can be elevated at the onset of anaphylaxis and in the hours following onset. The correct time of evaluation is at least 2 days after complete resolution of the allergic symptoms. Moreover, allergic disorders, chronic infections by helminths and myeloid neoplasms should be considered in the differential diagnosis when evaluating a patient with persistently elevated serum tryptase level [13].

\section{GI Symptoms}

In some cases, patients may present with recurrent diarrhea and abdominal pain after meals that resemble symptoms of food intolerance or food allergy. In other cases, relapsing gastric ulcer or gastroesophageal reflux may suggest an underlying hypersecretion of mediators. Although these manifestations are not life-threatening, they can be debilitating and have a strong impact on the quality of life of patients [14]. Endoscopy and multiple biopsies should be performed, even in absence of evident mucosal alterations, to exclude infections, celiac disease or, more rarely, GI stromal tumors.

\section{Bone Disease and Osteoporosis}

Bone pain is a commonly reported symptom, and the link to mastocytosis can be extremely hard. However, osteoporosis of unclear origin should raise the suspicion of mastocytosis, especially among men. In a population-based study, the authors found an increased risk of osteoporosis as early as 3 years before the diagnosis of mastocytosis; this risk remained consistently higher than that in an age- and sexmatched non-SM population during a 10-year follow-up [15]. The risk of fractures was only slightly augmented compared to the control population [15]. First-line evaluation comprises 


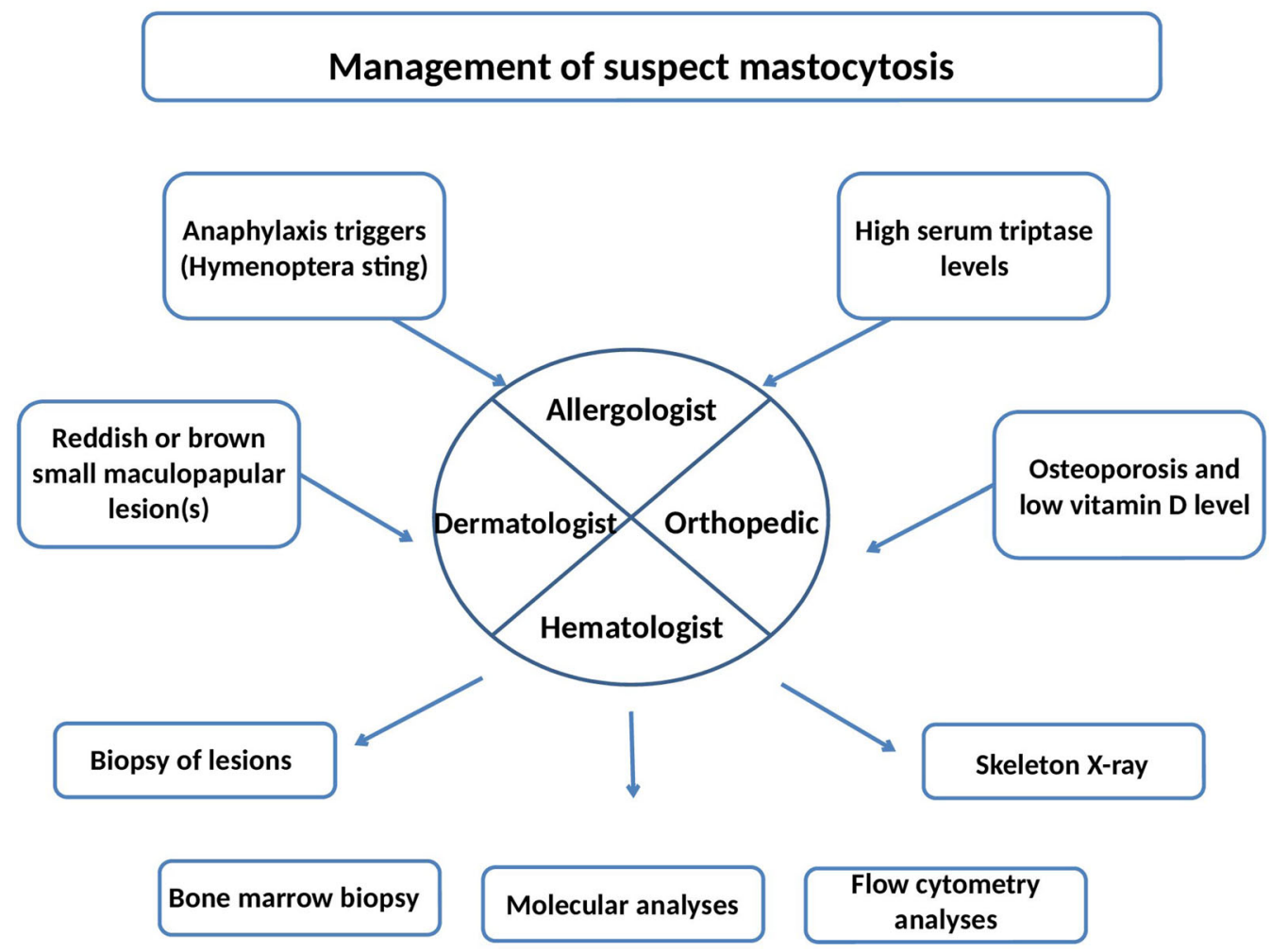

Fig. 1 Most frequent clinical presentations and required multidisciplinary approach for the management of suspected mastocytosis

dual-X-ray absorptiometry of the hip and lumbar vertebra for measuring bone mineral density and X-ray of the skeleton to exclude osteolysis and fractures.

In patients with persistent bone pain and unexplained osteoporosis, other clinical and/or laboratory findings to address the possible diagnosis of mastocytosis (skin lesions, serum tryptase) should be evaluated after the most relevant causes of osteoporosis are excluded. Therapy with oral bisphosphonates should be started according to their safety profile. In patients presenting with large osteolysis, a biopsy should be performed to exclude other neoplasms.

\section{Leukemic Presentation}

The first presentation of a mast cell disorder is only rarely a leukemic form. Symptoms are somewhat aspecific (weight loss, peripheral edema, ascites) and/or evocative of acute bone marrow impairment and organ infiltration, and can worsen rapidly. Cytopenias and circulating mast cells are almost always detectable, and some systemic manifestation of hypersensitivity is not infrequent even if less frequently than in SM [16]. Prognosis is dismal, and chemotherapy should be performed.

\section{MANAGEMENT}

Mastocytosis is often a multiorgan disease, and its correct management requires a multidisciplinary team of experienced consultants to provide the overall care of patients (Fig. 1).

\section{Molecular and Flow Cytometry Analyses}

The detection of the KIT D816V mutation, a minor WHO diagnostic criterion, is mandatory when systemic mastocytosis is suspected. The 
tyrosine kinase KIT is involved in hematopoiesis and is normally downregulated during lineage differentiation-the exception being in mast cells where its expression tends to remain high even in mature cells [17]. Activating mutations predominantly involve the intracellular domains, constitutively activate kinase phosphorylation and promote cell proliferation. More than $80 \%$ of patients with mastocytosis have the KITD816 V mutation, although other KIT mutations have been recently discovered [18].

Hoermann et al. evaluated the KITD816 V mutation burden by allele-specific oligonucleotide quantitative PCR (ASO-qPCR) and found that there was a higher mutation burden in patients with more advanced mastocytosis than in those with indolent disease [19]. Nevertheless, mutation burden did not correlate with tryptase levels or systemic symptoms, suggesting that the KITD816 V mutation is also present in non-mast cell hematopoietic lineage [19]. Moreover, using a cut-off of $2 \%$, these authors were able to identify two prognostic groups that differ for median survival (not reached in $<2 \%$ vs. reached in $6-3$ years in $>2 \%$, respectively).

Other mutations involved in myeloid neoplasms have been detected in mast cells disorders, prevalently in ASM and SM-AHNMD, such as those involving the TET2, SRSF2, ASXL1 and RUNX1 genes and, rarely, the JAK2 and RAS genes [20]. While these mutations seem to confer a worse prognosis overall, the number of mutations involved in the so-called R/A/S panel (mutations of SRSF2/ASXL1/RUNX1) correlate with lower survival rate and clinical aggressiveness [21].

Bone marrow analyses should also include flow cytometry to evaluate CD2 and/or CD25 surface antigens; these molecules are not normally expressed by mast cells, and their presence identifies the neoplastic clone. Moreover, an aberrant expression of CD30 on neoplastic mast cells has been reported in about $80 \%$ of patients with indolent and aggressive SM [22]. As CD30 is not expressed on normal mast cells, interest in this molecule as a therapeutic target is increasing.

\section{Radiological Tests}

Complete skeletal X-ray, DXA and abdomen ultrasound should be performed in all patients to exclude early and/or asymptomatic bone, liver and spleen involvement. Endoscopy should be performed when symptoms of GI ulcer or persistent diarrhea are reported.

\section{TREATMENT}

As clinical situations vary, treatment options range from symptomatic drugs, such as with anti-H1 receptors, steroids and UV irradiation, all strategies prevalently used in patients with $\mathrm{CM}$ or ISM, to cytoreductive treatment in patients with more aggressive disease to control life-threatening symptoms or organ damage. Prognosis also widely differs among patients diagnosed with mastocytosis, with those with $\mathrm{CM}$ having an almost normal life expectancy and those with MCL having a median overall survival (OS) of $<1$ year.

\section{Symptomatic treatment}

Anti-mediator agents, such as $\mathrm{H} 1$ and $\mathrm{H} 2$ antihistamines, anti-leukotriene drugs, proton pump inhibitors, cromolyn sodium and steroids, are almost always used to relief the symptoms of mast cell activation. Nevertheless, some patients are severely limited in their daily activities, even with optimal management by symptomatic dugs. The authors of a recent placebo-controlled trial reported that masitinib, an oral kinase inhibitor, was well tolerated and effective in controlling at least one symptom of mastocytosis in patients presenting with pruritus, flushing, depression and fatigue, as assessed using standardized qualitative questionnaires [23]. Some authors have reported on omalizumab use among heavily treated patients resistant to two or more concomitant anti-mediator drugs [24]. Subcutaneous monthly administration of this humanized monoclonal antibody, which binds IgE and reduces its contact with mast cells and basophil surface receptors, showed an impressive control of symptoms 
and rapid reduction of recurrent unexplained anaphylaxis [24].

Treatment with bisphosphonates should be promptly started in all patients presenting with low levels of vitamin D and radiological signs of osteoporosis, with the aim to reduce osteoclast activity and bone reabsorption [25].

\section{Systemic Therapy}

The first therapy for mastocytosis was interferon, which is also frequently used in the treatment of other myeloproliferative neoplasms for cytoreduction and disease burden control. Reported overall response rates (ORR) ranges from $20-30 \%$ up to $40 \%$, with a variable duration of response and high rate of relapse after therapy withdrawal [18]. Lim et al. reported an ORR of 47 and $57 \%$ with and without associated steroids, respectively, and a median duration of response of 12 months [26].

Cladribine is a purine analog that can damage DNA even in diseases with low proliferative rate. The authors of a recent multicenter French study involving 68 patients with ISM and ASM reported an ORR of $72 \%$ (92\% in ISM vs. 50\% in ASM), even if no complete response was detected [27]. The median time between consecutive cladribine courses was 52 (range 28-83) days, the median duration of response was 3.7 years and the median OS was 8.2 years [27].

Since the discovery of the underlying KIT mutation, tyrosine kinase inhibitors (TKI) have been tested in the treatment of mastocytosis. Although imatinib, a small molecule kinase inhibitor, has been proven to inhibit transformed cells in vitro, almost all KIT mutations have shown resistance to imatinibin vivo. Imatinib has, however, been demonstrated to be effective in vivo in those rare patients with wildtype KIT mast cell diseases [28].

In a phase II study of monotherapy with dasatinib, an ORR of 33\% was reported among 33 patients affected by SM, SM-AHD and MCL. Responses were durable, especially among ISM patients [29].

Midostaurin is an extremely potent TKI, that surpasses the resistance and inefficacy of other agents. A recent trial conducted among patients with ASM, SM-AHD and MCL and measurable organ damage reported an ORR of $60 \%$ and a median OS of 33.9 months [31]. In particular, patients with ASM had an ORR of $75 \%$, with a median duration of response and median OS not reached $(95 \%$ confidence interval [CI] 24.1 months to not estimated, and 95\% CI 28.7 months to not estimated). In patients with SM-AHNMD, the ORR was $58 \%$, with a median duration of response of 12.7 (95\% CI 7.4-31.4) months and median OS of 20.7 (95\% CI 16.0-44.4) months. In patients with MCL, the ORR dropped to $50 \%$, with a median duration of response not reached (95\% CI 3.6 months to not estimated) and median OS of 9.4 months (95\% CI 7.5 to not estimated) [30]. The authors of another study on 35 patients with ASM, SMAHNMD and MCL reported an ORR of 51\% and a median OS of 45 months from diagnosis, and identified a reduction in the c-KIT allele burden of $>25 \%$ to be predictive of better ORR and OS. Analyzing the number and characteristics of concomitant mutations, the same authors were able to demonstrate that all patients who progressed while on midostaurin therapy harbored a mutation in at least one gene of the $S / A / R$ panel [31].

Chemotherapy regimens like those used in acute leukemia induction are the only valid therapeutic option for patients with MCL or progressing ASM to obtain a reduction of disease burden or a transient disease control before transplant procedure [32].

\section{Hematopoietic Stem Cell Transplantation}

Unfortunately, systemic treatments are not curative in patients with ASM. In refractory or rapidly progressing cases, hematopoietic stem cell transplantation may be an option in younger patients for whom a donor is available. However, data are still lacking, and determination of the optimum timing of the transplant procedure may be challenging, particularly among patients with less aggressive disease and partial response to therapy. In a recent retrospective analysis, Ustun and colleagues reported on the outcome of 57 patients with ASM, SMAHNMD and MCL who received a transplant 
from different donor sources after myeloablative and non-myeloablative condition regimens [33]. The ORR was $70 \%$ but the complete remission rate was only $28 \%$; OS survival at 3 years was $57 \%$, ranging from $74 \%$ in patients with SM-AHNMD to $17 \%$ in those with MCL [33].

\section{New Drugs}

A number of new drugs have been studied in recent years in in vitro experiments with mutated and wild-type KIT cellular lines [34]. Following the identification of CD30 expression on the surface of the neoplastic mast cell in vitro and among some patients with SM, the role of brentuximab-vedotin was evaluated. Although the authors of a little case series reported some durable response [35], the role of brentuximab-vedotin in the treatment of SM is still being debated.

A more promising drug is BLU-285, a highly selective inhibitor of KIT and platelet-derived growth factor receptor alpha (PDGFR $\alpha$ ). The preliminary data on 12 patients with ASM show a marked reduction of disease burden, based on bone marrow infiltration, serum tryptase level and systemic symptoms [36]. Another KIT inhibitor, DCC-2618, has been reported to block mast cell growth and proliferation of the neoplastic non-mast cell marrow compartment in ASM and SM-AHNMD patients [37]. Both compounds are being tested in ongoing clinical trials.

\section{RESPONSE CRITERIA}

Defining global response criteria for mastocytosis remins a challenge due to the diverse clinical presentations of this condition. The therapeutic goal in treating the cutaneous and indolent forms of mastocytosis is the control of mediator release; in more the aggressive forms, ASM and MCL, the burden of disease needs to be reduced in order to prevent irreversible events, such as fracture, and restore organ function.

In 2003, Valent et al. proposed three categories of response [38]. Major responses defined undetectable mast cell infiltration with no organomegaly and reduced tryptase levels; reduction of mast cell infiltration with reduced organomegaly and reduced tryptase levels; or clinical improvement of $\mathrm{C}$ findings without any decrease in mast cell burden and tryptase levels. Partial responses defined two categories consisting of $<50 \%$ reduction and $>50 \%$ reduction, respectively, of one or more $\mathrm{C}$ finding without progression. No response defined stable disease or progression in one or more $\mathrm{C}$ finding, even with improvement of other parameters [38]. Although these categories started to standardize the evaluation of response, the selected criteria were not always exhaustive for mastocytosis overall and did not help to predict clinical evolution.

The Mayo Clinic group published a more comprehensive evaluation of response in 2007. This group proposed differentiating response criteria of CM/ISM and ASM, taking into consideration the reduction of skin involvement, the duration of resolution of mediator-related symptoms and improvement of organomegaly for both categories and the extent of organ damage and infiltration of bone marrow for ASM only [39]. Moreover, significant duration of responses, improvement of bone disease and general symptoms (ascites, hypoalbuminemia, weight loss) and load of supportive transfusion are still difficult to quantify [40].

\section{INVASIVE PROCEDURES}

Anesthesia can be concern for patients and physicians alike: drug administration, change in the room temperature and physical stimuli or emotional stress related to the procedure itself are all considered to be triggers for anaphylaxis. On the other hand, published reports describe $6 \%$ and $0.4 \%$ of hypersensitivity events during general versus local or epidural anesthesia, respectively [41]. Anaphylactic reactions following radiocontrast media are not higher in patients with mastocytosis than in the general population [42]. Delivery is reported to be a low-risk procedure of anaphylaxis, except for some allergic symptoms complicating $11 \%$ of pregnancies [43]. 
The decision to administers peri-operative prophylaxis with steroids and anti-H1 receptor drugs should be targeted to a single patient. A history of anaphylaxis, drug allergy, triggers for flushing and emotional distress should all be considered. Gently contact to patient, Control of room temperature and benzodiazepine administration may also be helpful to the perioperative management of patients [42].

\section{ACKNOWLEDGEMENTS}

Funding. No funding or sponsorship was received for this study or publication of this article.

Authorship. All named authors meet the International Committee of Medical Journal Editors (ICMJE) criteria for authorship for this article, take responsibility for the integrity of the work as a whole, and have given their approval for this version to be published.

Authorship Contributions. Marianna Criscuolo wrote the paper; Marianna Criscuolo, Luana Fianchi and Alessio ME Maraglino reviewed the literature; Livio Pagano revised the paper.

Disclosures. The authors Marianna Criscuolo, Luana Fianchi, Alessio ME Maraglino and Livio Pagano have nothing to disclose.

Compliance with Ethics Guidelines. This article is based on previously conducted studies and does not contain any studies with human participants or animals performed by any of the authors.

Open Access. This article is distributed under the terms of the Creative Commons Attribution-NonCommercial 4.0 International License (http://creativecommons.org/licenses/ by-nc/4.0/), which permits any noncommercial use, distribution, and reproduction in any medium, provided you give appropriate credit to the original author(s) and the source, provide a link to the Creative Commons license, and indicate if changes were made.

\section{REFERENCES}

1. Cohen SS, Skovbo S, Vestergaard H, Kristensen T, Møller M, Bindslev-Jensen C, et al. Epidemiology of systemic mastocytosis in Denmark. Br J Haematol. 2014;166(4):521-8.

2. Horny HP, Metcalfe DD, Bennett JM, et al. Mastocytosis. In: Swerdlow SH, Campo E, Harris NL, Jaffe ES, Pileri SA, Stain H, Thiele J, Vardiman JW (eds) WHO classification of tumors of hematopoietic and lymphoid tissues. Lyon: International Agency for Research and Cancer (IARC); 2008. p. 54-63.

3. Hartmann K, Escribano L, Grattan C, Brockow K, Carter MC, Alvarez-Twose I, et al. Cutaneous manifestations in patients with mastocytosis: consensus report of the European Competence Network on Mastocytosis; the American Academy of Allergy, Asthma \& Immunology; and the European Academy of Allergology and Clinical Immunology. J Allergy Clin Immunol. 2016;137(1):35-45.

4. Weber A, Knop J, Maurer M. Pattern analysis of human cutaneous mast cell populations by total body surface mapping. $\mathrm{Br} \mathrm{J}$ Dermatol. 2003;148(2):224-8.

5. Brockow K, Akin C, Huber M, Metcalfe DD. Assessment of the extent of cutaneous involvement in children and adults with mastocytosis: relationship to symptomatology, tryptase levels, and bone marrow pathology. J Am Acad Dermatol. 2003;48(4):508-16.

6. González de Olano D, de la Hoz Caballer B, Núñez López R, Sánchez Muñoz L, Cuevas Agustín M, Diéguez MC, et al. Prevalence of allergy and anaphylactic symptoms in 210 adult and pediatric patients with mastocytosis in Spain: a study of the Spanish network on mastocytosis (REMA). Clin Exp Allergy. 2007;37(10):1547-55.

7. Brockow K, Jofer C, Behrendt H, Ring J. Anaphylaxis in patients with mastocytosis: a study on history, clinical features and risk factors in 120 patients. Allergy. 2008;63(2):226-32.

8. Gülen T, Hägglund H, Dahlén B, Nilsson G. High prevalence of anaphylaxis in patients with systemic mastocytosis - a single-centre experience. Clin Exp Allergy. 2014;44(1):121-9.

9. Aberer E, Savic S, Bretterklieber A, Reiter H, Berghold A, Aberer W. Disease spectrum in patients with 
elevated serum tryptase levels. Australas J Dermatol. 2015;56(1):7-13.

10. Bonadonna P, Zanotti R, Pagani M, Caruso B, Perbellini $\mathrm{O}$, Colarossi $\mathrm{S}$, et al. How much specific is the association between hymenoptera venom allergy and mastocytosis? Allergy. 2009;64(9):1379-82.

11. Bonadonna P, Perbellini O, Passalacqua G, Caruso B, Colarossi S, Dal Fior D, et al. Clonal mast cell disorders in patients with systemic reactions to Hymenoptera stings and increased serum tryptase levels. J Allergy Clin Immunol. 2009;123(3):680-6.

12. Broesby-Olsen $\mathrm{S}$, Kristensen $\mathrm{T}$, Vestergaard $\mathrm{H}$, Brixen K, Møller MB, Bindslev-Jensen C, Mastocytosis Centre Odense University Hospital (MastOUH). KIT D816V mutation burden does not correlate to clinical manifestations of indolent systemic mastocytosis. J Allergy Clin Immunol. 2013;132(3):723-8.

13. Valent P, Aberer E, Beham-Schmid C, Fellinger C, Fuchs W, Gleixner KV, et al. Guidelines and diagnostic algorithm for patients with suspected systemic mastocytosis: a proposal of the Austrian competence network (AUCNM). Am J Blood Res. 2013;3(2):174-80.

14. Nanagas VC, Kovalszki A. Gastrointestinal manifestations of hypereosinophilic syndromes and mast cell disorders: a comprehensive review. Clin Rev Allergy Immunol. 2018. https://doi.org/10. 1007/s12016-018-8695-y .

15. Broesby-Olsen S, Farkas DK, Vestergaard H, Hermann AP, Møller MB, Mortz CG, et al. Risk of solid cancer, cardiovascular disease, anaphylaxis, osteoporosis and fractures in patients with systemic mastocytosis: a nationwide population-based study. Am J Hematol. 2016;91(11):1069-75.

16. Valent P, Sotlar K, Sperr WR, Escribano L, Yavuz S, Reiter A, et al. Refined diagnostic criteria and classification of mast cell leukemia (MCL) and myelomastocytic leukemia (MML): a consensus proposal. Ann Oncol. 2014;25(9):1691-700.

17. Valent P, Spanblöchl E, Sperr WR, Sillaber C, Zsebo $\mathrm{KM}$, Agis $\mathrm{H}$, et al. Induction of differentiation of human mast cells from bone marrow and peripheral blood mononuclear cells by recombinant human stem cell factor/kit-ligand in long-term culture. Blood. 1992;80(9):2237-45.

18. Pardanani A. Systemic mastocytosis in adults: 2017 update on diagnosis, risk stratification and management. Am J Hematol. 2016;91(11):1146-59.

19. Hoermann G, Gleixner KV, Dinu GE, Kundi M, Greiner G, Wimazal F, et al. The KIT D816V allele burden predicts survival in patients with mastocytosis and correlates with the WHO type of the disease. Allergy. 2014;69(6):810-3.

20. Jawhar M, Schwaab J, Schnittger S, Sotlar K, Horny HP, Metzgeroth G, et al. Molecular profiling of myeloid progenitor cells in multi-mutated advanced systemic mastocytosis identifies KIT $\mathrm{D} 816 \mathrm{~V}$ as a distinct and late event. Leukemia. 2015;29(5):1115-22.

21. Jawhar M, Schwaab J, Schnittger S, Meggendorfer M, Pfirrmann M, Sotlar K, et al. Additional mutations in SRSF2, ASXL1 and/or RUNX1 identify a high-risk group of patients with KIT D816V(+) advanced systemic mastocytosis. Leukemia. 2016;30(1):136-43.

22. Morgado JM, Perbellini O, Johnson RC, Teodósio C, Matito A, Álvarez-Twose I, et al. CD30 expression by bone marrow mast cells from different diagnostic variants of systemic mastocytosis. Histopathology. 2013;63(6):780-7.

23. Lortholary O, Chandesris MO, Bulai Livideanu C, Paul C, Guillet G, Jassem E, Niedoszytko M, et al. Masitinib for treatment of severely symptomatic indolent systemic mastocytosis: a randomised, placebo-controlled, phase 3 study. Lancet. 2017;389(10069):612-20.

24. Broesby-Olsen S, Vestergaard H, Mortz CG, Jensen B, Havelund T, Hermann AP, et al. Omalizumab prevents anaphylaxis and improves symptoms in systemic mastocytosis: efficacy and safety observations. Allergy. 2018;73(1):230-8.

25. Rossini M, Zanotti R, Orsolini G, Tripi G, Viapiana O, Idolazzi L, et al. Prevalence, pathogenesis, and treatment options for mastocytosis-related osteoporosis. Osteoporos Int. 2016;27(8):2411-21.

26. Lim KH, Pardanani A, Butterfield JH, Li CY, Tefferi A. Cytoreductive therapy in 108 adults with systemic mastocytosis: outcome analysis and response prediction during treatment with interferon-alpha, hydroxyurea, imatinib mesylate or 2-chlorodeoxyadenosine. Am J Hematol. 2009;84(12):790-4.

27. Barete S, Lortholary O, Damaj G, Hirsch I, Chandesris MO, Elie C, et al. Long-term efficacy and safety of cladribine (2-CdA) in adult patients with mastocytosis. Blood. 2015;126(8):1009-16.

28. Akin C, Fumo G, Yavuz AS, et al. A novel form of mastocytosis associated with a transmembrane c-kit mutation and response to imatinib. Blood. 2004;103:3222-5.

29. Verstovsek S, Tefferi A, Cortes J, O’Brien S, GarciaManero G, Pardanani A, et al. Phase II study of 
dasatinib in Philadelphia chromosome-negative acute and chronic myeloid diseases, including systemic mastocytosis. Clin Cancer Res. 2008;14(12):3906-15.

30. Gotlib J, Kluin-Nelemans HC, George TI, Akin C, Sotlar K, Hermine O, et al. Efficacy and safety of midostaurin in advanced systemic mastocytosis. N Engl J Med. 2016;374(26):2530-41.

31. Jawhar M, Schwaab J, Naumann N, Horny HP, Sotlar K, Haferlach T, et al. Response and progression on midostaurin in advanced systemic mastocytosis: KIT D816V and other molecular markers. Blood. 2017;130(2):137-45.

32. Valent P, Akin C, Hartmann K, Nilsson G, Reiter A, Hermine $\mathrm{O}$, et al. Advances in the classification and treatment of mastocytosis: current status and outlook toward the future. Cancer Res. 2017;77(6):1261-70.

33. Ustun C, Reiter A, Scott BL, Nakamura R, Damaj G, Kreil S, et al. Hematopoietic stem-cell transplantation for advanced systemic mastocytosis. J Clin Oncol. 2014;32(29):3264-74.

34. Arock M, Wedeh G, Hoermann G, Bibi S, Akin C, Peter B, et al. Preclinical human models and emerging therapeutics for advanced systemic mastocytosis. Haematologica. 2018. https://doi.org/10. 3324/haematol.2018.195867.

35. Borate U, Mehta A, Reddy V, Tsai M, Josephson N, Schnadig I. Treatment of CD30-positive systemic mastocytosis with brentuximab vedotin. Leuk Res. 2016;44:25-31.

36. Drummond MW, DeAngelo DJ, Deininger MW, Radia D, Quiery AT, Hexner EO, et al. Preliminary safety and clinical activity in a phase 1 study of BLU-285, a potent, highly-selective inhibitor of KIT $\mathrm{D} 816 \mathrm{~V}$ in advanced systemic mastocytosis (SM). Abstract \#477. In: 2016 ASH Annual Meeting, December 4, 2016. San Diego.
37. Schneeweiss M, Peter B, Bibi S, Eisenwort G, Smiljkovic D, Blatt K, et al. The KIT and PDGFRA switchcontrol inhibitor DCC-2618 blocks growth and survival of multiple neoplastic cell types in advanced mastocytosis. Haematologica. 2018;103(5):799-809.

38. Valent P, Akin C, Sperr WR, Escribano L, Arock M, Horny HP, et al. Aggressive systemic mastocytosis and related mast cell disorders: current treatment options and proposed response criteria. Leuk Res. 2003;27(7):635-41.

39. Pardanani A, Tefferi A. A critical reappraisal of treatment response criteria in systemic mastocytosis and a proposal for revisions. Eur J Haematol. 2010;84(5):371-8.

40. Gotlib J, Pardanani A, Akin C, Reiter A, George T, Hermine $\mathrm{O}$, et al. International Working GroupMyeloproliferative Neoplasms Research and Treatment (IWG-MRT) \& European Competence Network on Mastocytosis (ECNM) consensus response criteria in advanced systemic mastocytosis. Blood. 2013;121(13):2393-401.

41. Matito A, Morgado JM, Sánchez-López P, ÁlvarezTwose I, Sánchez-Muñoz L, Orfao A, et al. Management of anesthesia in adult and pediatric mastocytosis: a study of the Spanish network on mastocytosis (REMA) based on 726 anesthetic procedures. Int Arch Allergy Immunol. 2015;167(1):47-56.

42. Hermans MAW, Arends NJT, Gerth van Wijk R, van Hagen PM, Kluin-Nelemans HC, Oude Elberink HNG, et al. Management around invasive procedures in mastocytosis: An update. Ann Allergy Asthma Immunol. 2017;119(4):304-9.

43. Matito A, Álvarez-Twose I, Morgado JM, SánchezMuñoz L, Orfao A, Escribano L. Clinical impact of pregnancy in mastocytosis: a study of the Spanish network on mastocytosis (REMA) in 45 cases. Int Arch Allergy Immunol. 2011;156(1):104-11. 